\title{
Population genetics of Leishmania (Leishmania) major DNA isolated from cutaneous leishmaniasis patients in Pakistan based on multilocus microsatellite typing
}

Mohammad Zahangir Alam,2, Abdul Manan Bhutto ${ }^{3}$, Farooq Rahman Soomro4, Javed Hussain Baloch4, Ryo Nakao ${ }^{5}$, Hirotomo Kato ${ }^{1}$, Gabriele Schönian ${ }^{6}$, Hiroshi Uezato ${ }^{7}$, Yoshihisa Hashiguchi ${ }^{8,9}$ and Ken Katakura ${ }^{{ }^{*}}$

\begin{abstract}
Background: Cutaneous leishmaniasis (CL) is a major and fast increasing public health problem, both among the local Pakistani populations and the Afghan refugees in camps. Leishmania (Leishmania) major is one of the etiological agents responsible for $\mathrm{CL}$ in Pakistan. Genetic variability and population structure have been investigated for 66 DNA samples of $L$. (L.) major isolated from skin biopsy of $C L$ patients.

Methods: Multilocus microsatellite typing (MLMT), employing 10 independent genetic markers specific to L. (L.) major, was used to investigate the genetic polymorphisms and population structures of Pakistani L. (L.) major DNA isolated from $C L$ human cases. Their microsatellite profiles were compared to those of 130 previously typed strains of $L$. (L.) major from various geographical localities.

Results: All the markers were polymorphic and fifty-one MLMT profiles were recognized among the 66 L. (L.) major DNA samples. The data displayed significant microsatellite polymorphisms with rare allelic heterozygosities. A Bayesian model-based approach and phylogenetic analysis inferred two L. (L.) major populations in Pakistan. Thirty-four samples belonged to one population and the remaining $32 \mathrm{~L}$. (L.) major samples grouped together into another population. The two Pakistani L. (L.) major populations formed separate clusters, which differ genetically from the populations of L. (L.) major from Central Asia, Iran, Middle East and Africa.

Conclusions: The considerable genetic variability of $L$. (L.) major might be related to the existence of different species of sand fly and/or rodent reservoir host in Sindh province, Pakistan. A comprehensive study of the epidemiology of $\mathrm{CL}$ including the situation or spreading of reservoirs and sand fly vectors in these foci is, therefore, warranted.
\end{abstract}

Keywords: Leishmania (Leishmania) major, Microsatellite typing, Population genetics, Pakistan

\section{Background}

Leishmaniases are a group of parasitic diseases caused by obligatory, intracellular, protozoan parasites of the genus Leishmania. Cutaneous leishmaniasis (CL) is more widely distributed, with about one-third of cases occurring in each of three epidemiological regions, the Americas,

\footnotetext{
* Correspondence: kenkata@vetmed.hokudai.ac.jp

'Department of Disease Control, Laboratory of Parasitology, Graduate School of Veterinary Medicine, Hokkaido University, Kita 18 Nishi 9, Kita-ku, Sapporo 060-0818, Japan

Full list of author information is available at the end of the article
}

the Mediterranean basin, and western Asia from the Middle East to Central Asia [1]. Pakistan, a tropical and subtropical country located in the northwest of South Asia, is highly endemic for the leishmaniases. $\mathrm{CL}$ is a major and fast increasing public health problem, both among the local Pakistani populations and the Afghan refugees in camps. Its extensive spread has been associated with mass migration, from endemic to non-endemic areas and vice versa, and with Afghan refugees from areas where CL is highly endemic [2]. Recently, more than 1200 cases of CL were identified 
in the lowland of Sindh province, the southern part of Pakistan [3]. Two types of CL, anthroponotic (ACL) and zoonotic (ZCL) are prevalent in Pakistan. Zoonotic CL caused by Leishmania (Leishmania) major mainly occurs in rural and semi-urban areas of Balochistan and neighboring Punjab and Sindh provinces. Clinically, the disease has been associated with "moist or wet-type" lesions, but unusual clinical forms have also been reported $[4,5]$.

The parasites from the lowland areas of Sindh province were assigned to $L$. (L.) major by multilocus enzyme electrophoresis (MLEE) and intra-specific polymorphisms were reported among these $L$. (L.) major isolates [6]. Typing of $L$. (L.) major parasites from Pakistan by using PCR-based methods targeting nuclear multicopy sequences or antigencoding genes, followed by subsequent search for polymorphism by sequencing showed little genetic variation within this species [7]. For population genetic studies and differentiation of closely related parasites, markers of higher discriminatory power are needed. Multilocus microsatellite typing (MLMT) has become an increasingly important tool for molecular typing and population genetic studies in different species of the genus Leishmania and data obtained by MLMT are highly informative in an eco-geographical context [8-12]. MLMT has the advantage of providing reproducible results that can be stored as databases for sharing among different laboratories, including its use for predicting evolutionary origin of the Leishmania parasites $[11,13]$. Recently, microsatellite markers were used to infer the population structure of $L$. (L.) major on a global scale [12] and on a country-wide scale in Iran [14].

In the present study, we used a panel of previously described microsatellite markers [12] to investigate the genetic variation and population structure of Pakistani $L$. (L.) major isolates, and to compare them with strains from other endemic foci in different geographical areas.

\section{Methods}

\section{Leishmania DNA}

Sixty-six L. (L.) major DNA samples isolated from Pakistani CL cases during the period of 2003 to 2004 were analyzed in this study. The patients resided in different villages and cities of Larkana, Shahdadkot and Dadu districts of Sindh province or part of Balochistan province (Figure 1) [15,16]. For 64 samples, the genomic DNA was extracted from amastigotes in skin biopsy specimens using GenomicPrep ${ }^{\mathrm{Tm}}$ cell and a tissue DNA Isolation Kit (Amersham Pharmacia Biotech, Piscataway, NJ, USA), according to the manufacturer's instructions [15]. Furthermore, for two strains previously identified as $L$. (L.) major based on parasite-specific kinetoplast DNA (kDNA) sequences [15] the DNA was isolated from cultured promastigotes by using a phenol-chloroform extraction method described previously [17] with some modifications. The source, designation and geographic origin of the parasites from Pakistan analysed in this study are listed in Table 1.

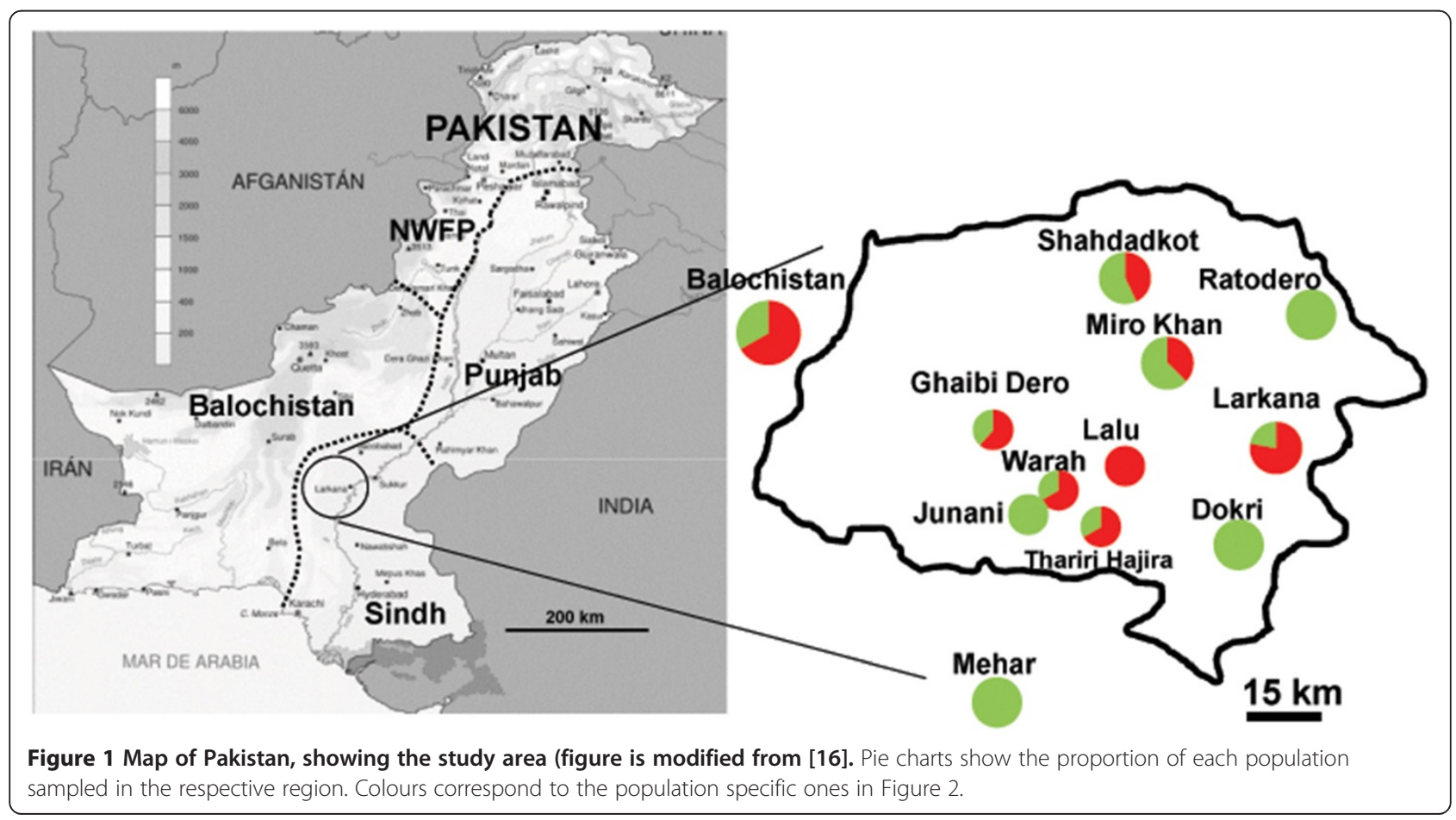


Table 1 Samples of $L$. (L.) major analyzed in this study and their multilocus microsatellite (MLMT) profiles

\begin{tabular}{|c|c|c|c|c|c|c|c|c|c|c|c|c|c|}
\hline Genotype & Population & L.(L.) major samples & Origin & 4GTG & 27GTG & $36 \mathrm{GTG}$ & 39GTG & 45GTG & $1 \mathrm{GC}$ & 28AT & 71AT & 1GACA & $1 \mathrm{CA}$ \\
\hline 1 & POP-A & P01-43 & Ghaibi Dero & 7 & 9 & 8 & 2 & 9 & 8 & 18 & 11 & 6 & 18 \\
\hline 2 & POP-A & P01-44 & Unknown & 7 & 9 & 9 & 2 & 9 & 8 & 10 & 11 & 6 & 19 \\
\hline 3 & POP-B & P01-45 & Miro Khan & 7 & 9 & 8 & 2 & 9 & 8 & 10 & 12 & 6 & 19 \\
\hline 4 & POP-A & P01-46 & Shahdadkot & 7 & 9 & 8 & 2 & 9 & 8 & 10 & 11 & 6 & 18 \\
\hline 5 & POP-B & P01-48 & Ghaibi Dero & 7 & 9 & 8 & 2 & 9 & 8 & 18 & 12 & 6 & 19 \\
\hline 6 & POP-A & P01-49 & Ghaibi Dero & 7 & 9 & 9 & 3 & 9 & 8 & 18 & 11 & 6 & 19 \\
\hline 7 & POP-B & P01-50 & Miro Khan & 7 & 9 & 9 & 2 & 9 & 8 & .. & 12 & 6 & 19 \\
\hline 4 & POP-A & P01-51 & Larkana & 7 & 9 & 8 & 2 & 9 & 8 & 10 & 11 & 6 & 18 \\
\hline 8 & POP-A & P01-52 & Warah & 7 & 9 & 9 & 2 & 9 & 8 & 18 & 11 & 6 & 19 \\
\hline 9 & POP-A & P01-59 & Ghaibi Dero & 7 & 9 & 9 & 2 & 9 & 8 & 10 & 11 & 6 & 18 \\
\hline 8 & POP-A & P01-61 & Miro Khan & 7 & 9 & 9 & 2 & 9 & 8 & 18 & 11 & 6 & 19 \\
\hline 10 & POP-B & P01-62 & Junani & 7 & 9 & 9 & 2,3 & 9 & 8 & 8 & 12 & 6 & 18 \\
\hline 11 & POP-A & P01-64 & Larkana & 7 & 9 & 9 & 2 & 9 & 8 & 10 & 11 & 6 & 20 \\
\hline 2 & POP-A & P01-66 & Lalu & 7 & 9 & 9 & 2 & 9 & 8 & 10 & 11 & 6 & 19 \\
\hline 12 & POP-B & P01-68 & Mehar & 7 & 9 & 8 & 2 & 9 & 8 & 8 & 12 & 6 & 18 \\
\hline 13 & POP-B & P02-01 & Mehar & 7 & 9 & 8 & 2 & 9 & 8 & 10 & 12 & 6 & 20 \\
\hline 9 & POP-A & P02-02 & Balochistan & 7 & 9 & 9 & 2 & 9 & 8 & 10 & 11 & 6 & 18 \\
\hline 14 & POP-B & P02-05 & Thariri Hajira & 7 & 8,9 & 8 & 2 & 18 & 8 & 18 & 12 & 6 & .. \\
\hline 15 & POP-A & P02-10 & Shahdadkot & 7 & 9 & 9 & 2 & 9 & 8 & 18 & 11 & 6 & 19 \\
\hline 16 & POP-A & P02-13 & Shahdadkot & 7 & 9 & 7,8 & 2 & 9 & 8 & 10 & 11 & 6 & 21 \\
\hline 17 & POP-B & P02-14 & Unknown & 7 & 8,9 & 8 & 2 & 9 & 8 & 18 & 12 & 6 & 18 \\
\hline 18 & POP-A & P02-15 & Warah & 7 & 9 & 9 & 2 & 9 & 8 & 18 & 11 & 6 & 20 \\
\hline 19 & POP-A & P02-17 & Lalu & 7 & 9 & 8 & 2 & 9 & 8 & 10 & 11 & 6 & 19 \\
\hline 11 & POP-A & P02-18 & Ghaibi Dero & 7 & 9 & 9 & 2 & 9 & 8 & 10 & 11 & 6 & 20 \\
\hline 9 & POP-A & P02-20 & Miro Khan & 7 & 9 & 9 & 2 & 9 & 8 & 10 & 11 & 6 & 18 \\
\hline 20 & POP-B & P02-25 & Miro Khan & 7 & 9 & 9 & 2 & 9 & 8 & .. & 12 & 6 & 18 \\
\hline 21 & POP-B & P02-26 & Dokri & 7 & 9 & 9 & 2 & 9 & 8 & 8,10 & 12 & 6 & 19 \\
\hline 9 & POP-A & P02-27 & Ghaibi Dero & 7 & 9 & 9 & 2 & 9 & 8 & 10 & 11 & 6 & 18 \\
\hline 22 & POP-B & P02-30 & Ratodero & 7 & 9 & 9 & 2 & 9 & 8 & 8 & 12 & 6 & 18 \\
\hline 23 & POP-A & P02-35 & Ghaibi Dero & 7 & 8,9 & 9 & 2 & 9 & 8 & 10 & 11 & 6 & 18 \\
\hline 24 & POP-B & P02-36 & Dokri & 7 & 9 & 8 & 2 & 18 & 8 & 18 & 12 & 6 & 18 \\
\hline 9 & POP-A & P02-39 & Ghaibi Dero & 7 & 9 & 9 & 2 & 9 & 8 & 10 & 11 & 6 & 18 \\
\hline 25 & POP-B & P02-41 & Unknown & 7 & 9 & 8 & 2 & 18 & 8 & 18 & 12 & 6 & 19 \\
\hline 2 & POP-A & P02-42 & Thariri Hajira & 7 & 9 & 9 & 2 & 9 & 8 & 10 & 11 & 6 & 19 \\
\hline 26 & POP-B & P02-43 & Ghaibi Dero & 7 & 9 & 9 & 2 & 9 & 8 & 8 & 12 & 6 & 21 \\
\hline 27 & POP-B & P02-44 & Ghaibi Dero & 7 & 9 & 12 & 2 & 18 & 8 & 18 & 12 & 6 & 19 \\
\hline 28 & POP-B & P02-46 & Miro Khan & 7,10 & 9 & 9 & 2 & 9 & 8 & 8 & 12 & 6 & 21 \\
\hline 29 & POP-B & P02-54 & Warah & 7 & 9 & 9 & 2 & 9 & 8 & 10 & 12 & 6 & 18 \\
\hline 30 & POP-B & P02-55 & Dokri & 7 & 9 & 9,10 & 2 & 9 & 8 & 8 & 12 & 6 & 19 \\
\hline 31 & POP-B & P02-65 & Shahdadkot & 7 & 9 & 8 & 2 & 9 & 8 & 8,10 & 12 & 6 & 20 \\
\hline 2 & POP-A & P02-66 & Balochistan & 7 & 9 & 9 & 2 & 9 & 8 & 10 & 11 & 6 & 19 \\
\hline 32 & POP-B & P02-68 & Ghaibi Dero & 7 & 9 & 8 & 2 & 9 & 8 & 10 & 12 & 6 & 14 \\
\hline 33 & POP-B & P02-69 & Junani & 7 & 9 & 12 & 2 & 9 & 8 & 18 & 12 & 6 & 19 \\
\hline 34 & POP-B & P02-72 & Larkana & 7 & 9 & 9 & 2 & 9 & 8 & 8 & 12 & 6 & 20 \\
\hline
\end{tabular}


Table 1 Samples of $L$. (L.) major analyzed in this study and their multilocus microsatellite (MLMT) profiles (Continued)

\begin{tabular}{|c|c|c|c|c|c|c|c|c|c|c|c|c|c|}
\hline 35 & POP-A & P02-79 & Miro Khan & 7 & 9 & 9 & 2 & .. & 8 & 18 & 11 & 6 & 18 \\
\hline 36 & POP-B & P02-86 & Dokri & 7 & 9 & 8 & 2 & 18 & 8 & 18 & 12 & 6 & 21 \\
\hline 19 & POP-A & P02-89 & Lalu & 7 & 9 & 8 & 2 & 9 & 8 & 10 & 11 & 6 & 19 \\
\hline 19 & POP-A & P02-90 & Thariri Hajira & 7 & 9 & 8 & 2 & 9 & 8 & 10 & 11 & 6 & 19 \\
\hline 22 & POP-B & P02-91 & Shahdadkot & 7 & 9 & 9 & 2 & 9 & 8 & 8 & 12 & 6 & 18 \\
\hline 37 & POP-A & P02-93 & Larkana & 7 & 9 & 8 & 2 & 9 & 8 & 18 & 11 & 6 & 21 \\
\hline 38 & POP-A & P02-94 & Larkana & 7 & 9 & 9 & 2 & 9 & 7 & 10 & 11 & 6 & 19 \\
\hline 39 & POP-B & P02-97 & Dokri & 7 & 9 & 8 & 2 & 9 & 8 & 18 & 12 & 6 & 21 \\
\hline 40 & POP-B & P02-99 & Mehar & 7 & 8,9 & 8 & 2 & 9 & 8 & 10 & 12 & 6 & 21 \\
\hline 41 & POP-A & P02-100 & Larkana & 7 & 9 & 8,10 & 2 & 9 & 8 & 10 & 11 & 6 & 18 \\
\hline 42 & POP-B & P02-108 & Larkana & 7 & 9 & 12 & 2 & 18 & 8 & 18 & 12 & 2 & 19 \\
\hline 43 & POP-B & P02-109 & Shahdadkot & 7 & 9 & 8 & 2 & 9 & 8 & 10 & 12 & 6 & 21 \\
\hline 44 & POP-B & P02-110 & Miro Khan & 7 & 8,9 & 8 & 2 & 9 & 7 & 10 & 12 & 6 & 18 \\
\hline 45 & POP-B & P02-119 & Ghaibi Dero & 7 & 9 & 9 & 2 & 18 & 8 & 18 & 12 & 2 & 18 \\
\hline 46 & POP-A & P02-123 & Unknown & 7 & 9 & 9 & 2 & 9 & 7 & 18 & 11 & 6 & 18 \\
\hline 47 & POP-A & P02-126 & Unknown & 7 & 9 & 9 & 2 & 18 & 8 & 10 & 11 & 6 & 21 \\
\hline 48 & POP-A & P02-130 & Unknown & 7 & 9 & 9 & 2 & 9 & 8 & 18 & 11 & 6 & 18 \\
\hline 9 & POP-A & P02-131 & Larkana & 7 & 9 & 9 & 2 & 9 & 8 & 10 & 11 & 6 & 18 \\
\hline 27 & POP-B & P02-133 & Unknown & 7 & 9 & 12 & 2 & 18 & 8 & 18 & 12 & 6 & 19 \\
\hline 49 & POP-A & P02-135 & Ghaibi Dero & 7 & 9 & 9 & 2 & 18 & 8 & 18 & 11 & 6 & 21 \\
\hline 50 & POP-A & MHOM/PK/03/SK2* & Larkana & 7 & 9 & 8 & 2 & 9 & 8 & 8,9 & 11 & 6 & 14 \\
\hline 51 & POP-B & MHOM/PK/03/SHD7* & Shahdadkot & 7 & 9 & 8 & 2 & 9 & 8 & 8,9 & 12 & 6 & 20 \\
\hline
\end{tabular}

*DNA from cultured parasites was used.

\section{Microsatellite genotyping}

Microsatellite genotyping was carried out using 10 variable microsatellite markers: 4gtg, 27gtg, 36gtg, 39gtg, $45 \mathrm{gtg}, 1 \mathrm{gc}, 28 \mathrm{at}, 71 \mathrm{at}, 1 \mathrm{gaca}$ and 1ca [12]. Fluorescence labeled forward primers were used for the amplification of microsatellite containing sequences applying the PCR condition described previously [12]. The size of the amplicons was determined by capillary electrophoresis with an automated ABI PRISM Gene Mapper sequencer (Applied Biosystem). In each run, a reference strain of $L$. (L.) major (MHOM/IL/1980/Friedlin) was included for which the microsatellite sizes for the 10 loci had been determined by sequencing. MLMType for each strain was obtained by compiling all alleles at each locus. The microsatellite profiles previously described for 130 strains of $L$. (L.) major originated from different geographical areas, including Africa, Central Asia, Iran and Middle East $[12,14]$ were used for comparison.

\section{Microsatellite data analysis}

Multilocus genotype data consists of the number of repeats in each microsatellite markers for each $L$. (L.) major DNA sample analyzed. Population structure was investigated by the STRUCTURE software, which applies a Bayesian model-based clustering approach [18]. This algorithm identifies genetically distinct clusters based on allelic frequencies and estimates the individual's membership co-efficient in each probabilistic population. A series of 10 runs was performed for each $K$ value between 1 and 10. The following parameters were used: burn in period of 20,000 iterations, 200,000 Markov Chain Monte Carlo iterations, admixture model. The most probable number of clusters was identified as suggested in the software manual by combining the analyses of the mean In $\operatorname{Pr}(\mathrm{X} / \mathrm{K})$ and the calculation of $\Delta \mathrm{K}$, which is based on the rate of change in the log probability of data between successive values of $K$. The peak of the $\Delta \mathrm{K}$ graph corresponds to the most probable number of populations in the data set [19].

Microsatellite-based genetic distances were calculated with the software packages MSA [20] and POPULATIONS (http://bioinformatics.org/ tryphon/populations/) by applying the proportion of shared alleles distance measure (Dps). Phylogenetic trees were constructed using Neighbourjoining (NJ) method by the help of the software programmes POPULATIONS 1.2.28 and MEGA [21].

Expected (He, gene diversity) and observed heterozygosity $(H \mathrm{O})$ as well as inbreeding co-efficient $(F \mathrm{is})$ and mean 
number of alleles were estimated using the Genetic Data Analysis software (http://hydrodictyon.eeb.uconn.edu/ people/plewis/software.php). The degree of genetic differentiation and gene flow among populations were assessed by calculating $F$ st values with corresponding $p$-values. Fst values higher than 0.25 indicate strong genetic differentiation [22].

\section{Ethical approval}

The parasitic DNA were isolated from the human patients' skin biopsy during the process of laboratory diagnosis of the disease at the outpatient clinic of the Department of Dermatology, Chandka Medical College (a constituent college of Shaheed Mohtarma Benazir Bhutto Medical University), Larkana, Sindh province, Pakistan. The patients were aware that their skin scrapings were needed for diagnosis of the disease using molecular diagnostic methods. Doctors obtained the written consent of the patients. The protocols used were approved by Chandka Medical College, Pakistan.

\section{Results}

Ten polymorphic microsatellite markers were used to analyze 66 samples of L. (L.) major collected from CL cases in endemic areas of Sindh and Balochistan province, Pakistan. In total, 51 different multilocus microsatellite profiles summarizing the repeat numbers obtained for the 10 microsatellite markers were assigned to the 66 Pakistani L. (L.) major samples tested, of which 43 were unique to individual strains and eight were shared by more than one strain (Table 1). Marker 1CA was the most polymorphic one presenting five alleles, whereas markers 4GTG, 27GTG, 39GTG, 45GTG, 1GC, 71AT and 1 GACA were least polymorphic presenting only two alleles for each.

Homozygous allele combinations predominated in the samples studied. Table 2 shows the variability measures of the 10 microsatellite loci, the observed and expected heterozygosities ( $\mathrm{Ho}$ and $\mathrm{He}$ ) as well as the inbreeding co-efficient ( $F$ is). The $F$ is values for 10 markers ranged from -0.0508 to 1 . Ho ranged from 0 to 0.1250 and $\mathrm{He}$ ranged from 0 to 0.7488 . All markers but one indicated a depletion of heterozygotes. The exception was the 27GTG marker, which revealed an excess of heterozygotes $(\mathrm{He}<\mathrm{Ho})$ corroborated by negative Fis.

Bayesian model-based analysis of the 66 samples using STRUCTURE showed that the optimal number of population was 2 (Figure 2). One population (POP-A) consisted of 34 samples; eight from Ghaibi Dero, seven from Larkana, three each from Shahdadkot, Miro Khan and Lalu, two each from Warah, Thariri Hajira and Balochistan, and four of unknown origin. The second population (POPB) comprised of 32 samples; five each from Ghaibi Dero, Dokri and Miro Khan, four from Shahdadkot, three from
Table 2 Descriptive statistics of the 10 microsatellite markers in the Pakistani L. (L.) major populations identified by STRUCTURE analysis

\begin{tabular}{|c|c|c|c|c|c|}
\hline Locus & Population & $A$ & $H_{\mathrm{e}}$ & $H_{\mathrm{o}}$ & Fis \\
\hline \multirow[t]{3}{*}{$\overline{4 G T G}$} & POP-A & 1 & 0 & 0 & 0 \\
\hline & POP-B & 2 & 0.0312 & 0.0312 & 0 \\
\hline & Mean & 1.5 & 0.0156 & 0.0156 & 0 \\
\hline \multirow[t]{3}{*}{$27 \mathrm{GTG}$} & POP-A & 2 & 0.0294 & 0.0294 & 0 \\
\hline & POP-B & 2 & 0.1190 & 0.1250 & -0.0508 \\
\hline & Mean & 2 & 0.0742 & 0.0772 & -0.0407 \\
\hline \multirow[t]{3}{*}{ 36GTG } & POP-A & 4 & 0.4376 & 0.0588 & 0.8673 \\
\hline & POP-B & 4 & 0.6145 & 0.0312 & 0.9499 \\
\hline & Mean & 4 & 0.5261 & 0.0450 & 0.9155 \\
\hline \multirow[t]{3}{*}{ 39GTG } & POP-A & 2 & 0.0579 & 0 & 1 \\
\hline & POP-B & 2 & 0.0312 & 0.0312 & 0 \\
\hline & Mean & 2 & 0.0445 & 0.0156 & 0.6534 \\
\hline \multirow[t]{3}{*}{ 45GTG } & POP-A & 2 & 0.1156 & 0 & 1 \\
\hline & POP-B & 2 & 0.3809 & 0 & 1 \\
\hline & Mean & 2 & 0.2482 & 0 & 1 \\
\hline \multirow[t]{3}{*}{ 1GC } & POP-A & 2 & 0.1123 & 0 & 1 \\
\hline & POP-B & 2 & 0.0615 & 0 & 1 \\
\hline & Mean & 2 & 0.0869 & 0 & 1 \\
\hline \multirow[t]{3}{*}{ 28AT } & POP-A & 4 & 0.4833 & 0.0294 & 0.9400 \\
\hline & POP-B & 4 & 0.6796 & 0.1000 & 0.8550 \\
\hline & Mean & 4 & 0.5814 & 0.0647 & 0.8903 \\
\hline \multirow[t]{3}{*}{ 71AT } & POP-A & 1 & 0 & 0 & 0 \\
\hline & POP-B & 1 & 0 & 0 & 0 \\
\hline & Mean & 1 & 0 & 0 & 0 \\
\hline \multirow[t]{3}{*}{$1 \mathrm{GACA}$} & POP-A & 1 & 0 & 0 & 0 \\
\hline & POP-B & 2 & 0.1190 & 0 & 1 \\
\hline & Mean & 2 & 0.0595 & 0 & 1 \\
\hline \multirow[t]{3}{*}{$1 \mathrm{CA}$} & POP-A & 5 & 0.6935 & 0 & 1 \\
\hline & POP-B & 5 & 0.7488 & 0 & 1 \\
\hline & Mean & 5 & 0.7212 & 0 & 1 \\
\hline \multirow[t]{3}{*}{ Overall } & POP-A & 2 & 0.1929 & 0.0117 & 0.9398 \\
\hline & POP-B & 3 & 0.2786 & 0.0318 & 0.8872 \\
\hline & Mean & 3 & 0.2358 & 0.0218 & 0.9088 \\
\hline
\end{tabular}

$A$, the number of alleles per locus; $H e$, the expected heterozygosity; $H o$, the observed heterozygosity; Fis, the inbreeding coefficient.

Mehar, two each from Larkana and Junani, one each from Warah, Thariri Hajira and Ratodero, and three of unknown origin. These two populations were significantly different as shown by their Fst value (0.4329) and $P$-value 0.0001 .

When merging the 66 Pakistani samples with $130 \mathrm{~L}$. (L.) major strains from 20 countries in Central Asia, Africa, Iran and Middle East, STRUCTURE analysis assigned these 196 strains to 8 different populations (Figure 3). Seven of these corresponded to the previously 

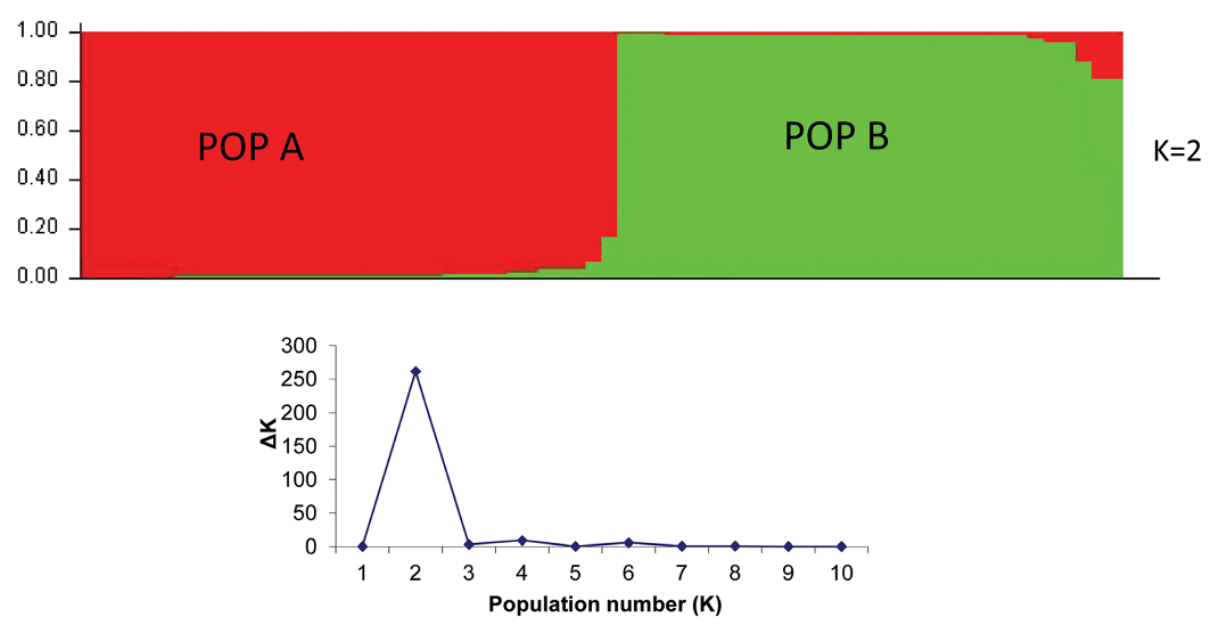

Figure 2 Estimated population structure for L. (L.) major from Pakistan as inferred by STRUCTURE software based on the data for 10 microsatellite markers obtained for the 66 L. (L.) major DNA samples studied herein. Each strain is represented by a single vertical line divided into $\mathrm{K}$ colours, where $\mathrm{K}$ is the number of populations assumed. Each colour represents one population, and the length of the colours segment shows the strain's estimated proportion of membership in that population. The derived graph for $\Delta K$ shows at $K=2$, indicating the existence of two populations in the investigated strain set.

exposed populations Central Asia/Iran 3, Middle East 1, Middle East 2, Africa 1, Africa 2, Iran 1, Iran 2 [14]. The eighth population comprised all strains from Pakistan which were found to be clearly distinct from the other strains of $L$. (L.) major studied so far. The Pakistani population was re-analysed separately by STRUCTURE and split into the two sub-populations described above (Figure 2).

The unrooted NJ tree constructed for the 196 strains of $L$. (L.) major using MEGA assigned the Pakistani samples to the same two clusters (Figure 4) as STRUCTURE analysis did. F-statistics revealed a significant amount of population structure among all of $L$. (L.) major clusters. The Fst values (Table 3 ) were significant and higher than
0.25 indicating very great genetic differentiation between the populations.

\section{Discussion}

In this study, the diversity and population genetic structure of strains of $L$. (L.) major from Pakistan was investigated, compared, and correlated with their geographical sources and prevailing environmental and ecological conditions. The present MLMT analysis revealed considerable genetic variation for the 66 Pakistani $L$. (L.) major DNA samples presenting 43 individual microsatellite profiles and eight were shared by several samples. This is a quite unexpected result because all the samples studied were from different villages and cities of Larkana, Shahdadkot and Dadu
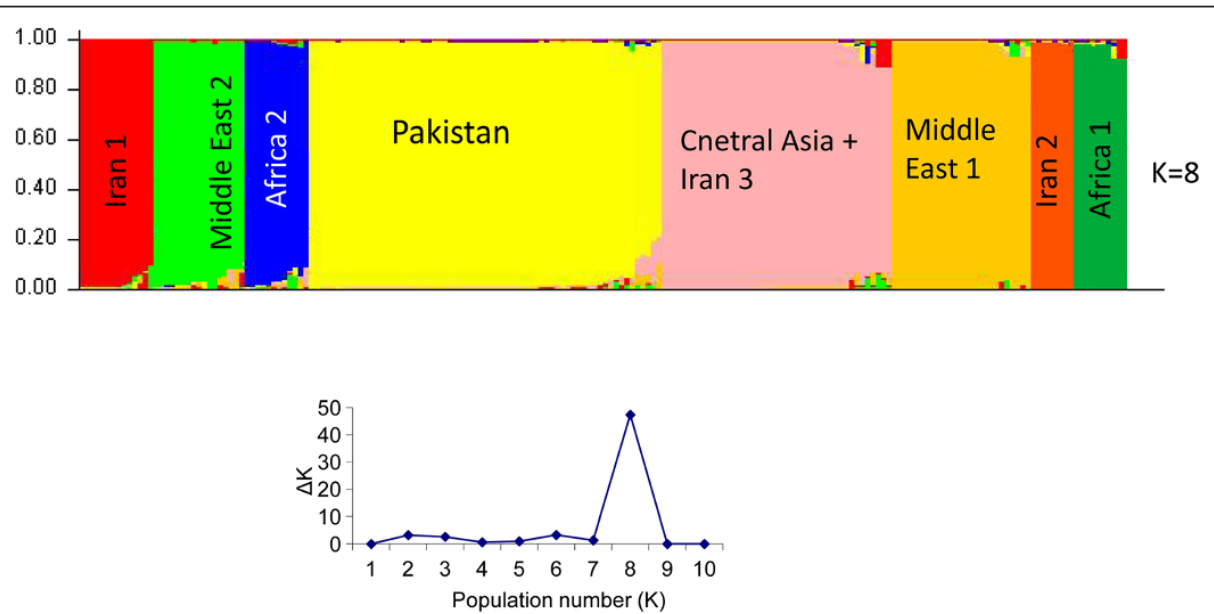

Figure 3 General population structure estimated for 196 L. (L.) major microsatellite profiles, including the 66 from Pakistan, compared in this study. In the bar plots each strain is represented by a single line divided into $\mathrm{K}$ colours, where $\mathrm{K}$ is the number of population. Isolates are organized by membership coefficients. 


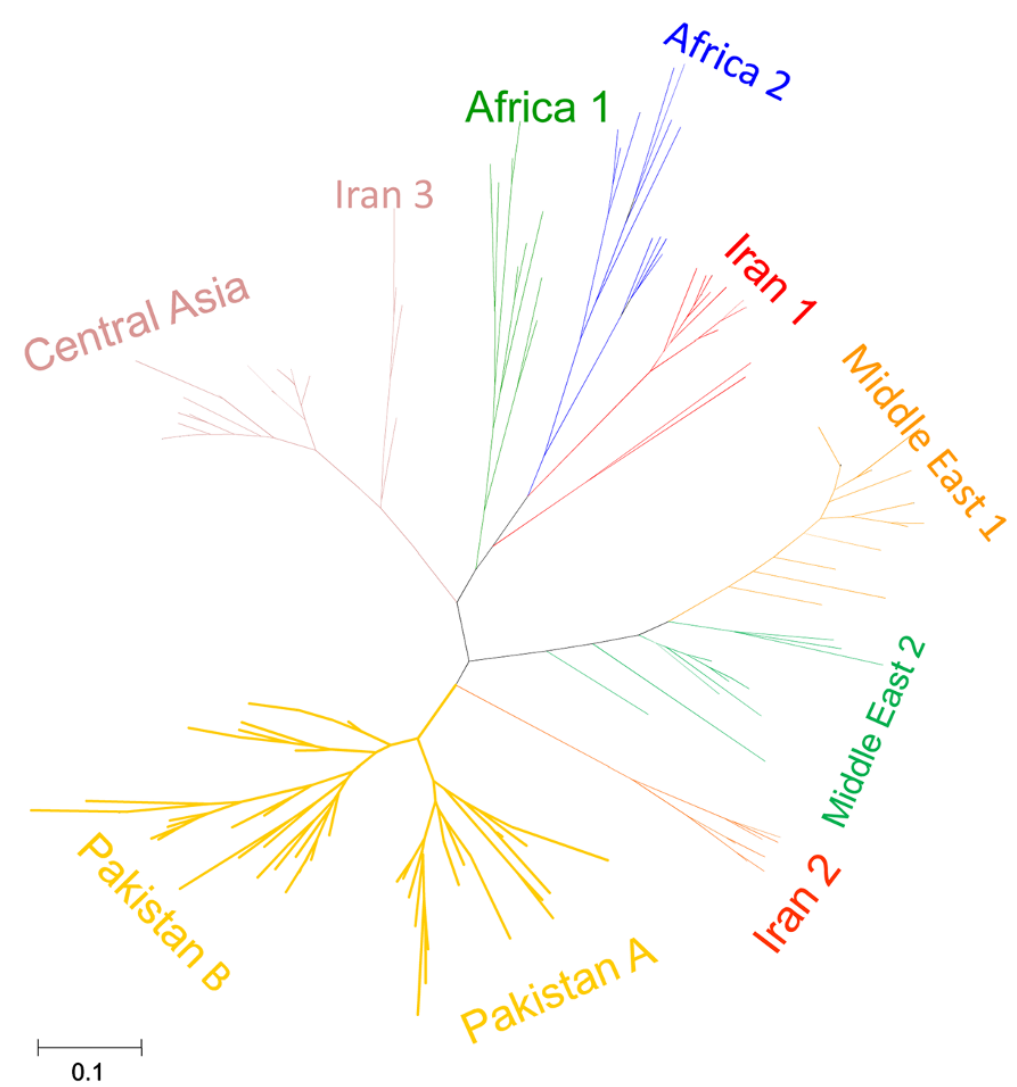

Figure 4 Neighbour-joining tree (unrooted) inferred from the Dps distances for the 196 L. (L.) major microsatellite profiles, including the 66 from Pakistan.

districts of Sindh province, except three that came from Balochistan province. Heterogeneity of Pakistani $L$. (L.) major is thus much higher as previously suggested when little intra-specific polymorphism was found for the parasites from the same area [6]. According to Fis, $H o$ and $H e$ values, microsatellite loci were mostly homozygous in the Pakistani sample set. Leishmania species have been considered to be clonal diploid organisms [23] in which Fis values are supposed to be negative due to heterozygote accumulation [24]. In this study, significant heterozygote deficiency was observed for most of the microsatellite loci. Heterozygote deficiency could result from population subdivision (Wahlund effect), presence of null alleles, natural selection, genetic conversion and inbreeding as discussed by Rougeron et al. (2009) [25]. In our study, almost all $L$. (L.) major DNA isolates came from the same area.

Table 3 Fst values (upper triangle) and corresponding $P$-values (lower triangle) for the populations and sub-populations of L. (L.) major as assumed by STRUCTURE

\begin{tabular}{llllllllll}
\hline Fst-values & Pakistan A & Pakistan B & Central Asia/Iran 3 & Africa 1 & Africa 2 & Middle East 1 & Middle East 2 & Iran 1 & Iran 2 \\
\hline Pakistan POP-A & 0 & 0.3351 & 0.7336 & 0.5924 & 0.6491 & 0.7483 & 0.6174 & 0.7174 & 0.6354 \\
Pakistan POP-B & 0.0001 & 0 & 0.6863 & 0.5326 & 0.5674 & 0.7013 & 0.5508 & 0.6056 & 0.5120 \\
Central Asia & 0.0001 & 0.0001 & 0 & 0.7066 & 0.6667 & 0.7094 & 0.7646 & 0.7861 & 0.7356 \\
Africa 1 & 0.0001 & 0.0001 & 0.0001 & 0 & 0.2626 & 0.5974 & 0.4807 & 0.4995 & 0.5301 \\
Africa 2 & 0.0001 & 0.0001 & 0.0001 & 0.0001 & 0 & 0.6336 & 0.5774 & 0.4630 & 0.5214 \\
Middle East 1 & 0.0001 & 0.0001 & 0.0001 & 0.0001 & 0.0001 & 0 & 0.62226 & 0.7819 & 0.7571 \\
Middle East 2 & 0.0001 & 0.0001 & 0.0001 & 0.0001 & 0.0001 & 0.0001 & 0 & 0.6704 & 0.6561 \\
Iran 1 & 0.0001 & 0.0001 & 0.0001 & 0.0001 & 0.0001 & 0.0001 & 0.0001 & 0 & 0.6592 \\
Iran 2 & 0.0001 & 0.0001 & 0.0001 & 0.0001 & 0.0001 & 0.0001 & 0.0001 & 0.0001 & 0 \\
\hline
\end{tabular}

Fst-value: 0-0.05 (little genetic differentiation), 0.05-0.15 (moderate genetic differentiation), 0.15-0.25 (great genetic differentiation), above 0.25 (very great genetic differentiation). 
Thus, the heterozygote deficiency found in the studied samples is unlikely to be due to the Wahlund effect (geographical isolation). In our study, 62 strains were amplified at all microsatellite loci and only four strains had one missing locus each (ca. $0.6 \%$ of all loci), but our data analysis using Micro-Checker software (http://www.microchecker. hull.ac.uk/) showed evidence for a null allele with few microsatellite loci (45GTG, 28AT and 1CA). Therefore, we cannot exclude the presence of heterozygote deficiency could result from null alleles. The high $F_{\mathrm{IS}}$ values observed across all polymorphic loci are also likely to be due to inbreeding. Selection may cause under-dominance by decreasing the fitness of heterozygous genotypes and gene conversion could lead to a transition from heterozygous to the homozygous stage [25]. In both cases, varying $F_{\mathrm{IS}}$ should be expected across our 10 non-coding microsatellite loci. As can be seen in Table 2, in locus 71 AT the expected and observed heterozygosities were zero for both POP-A and POP-B, and in locus 1GACA this was the case for POP-A. In locus 27GTG expected and observed heterozygosities were almost equal for both populations and the same was observed for POP-B in loci 4GTG and 39GTG. The resulting $F_{\mathrm{IS}}$ values were zero or close to zero suggesting that these loci are in equilibrium. All other loci had high

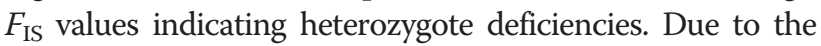
variance of $F$ is values across the microsatellite loci, we cannot exclude that selection or gene conversions have contributed to the high $F_{\text {IS }}$ values observed in this study. We would, however favor the hypothesis of significant inbreeding present in both Pakistani populations of $L$. major, as previously reported for different Leishmania parasites [25-27].

The Bayesian clustering approach implemented in STRUCTURE as well as the phylogenetic analysis based on genetic distances assigned the 66 Pakistani $L$. (L.) major samples to two populations (POP-A and POP-B). Fstatistics confirmed that these are genetically isolated populations. The two samples from Balochistan belonged to Population A. The Pakistani populations identified in the present study where clearly separated from the populations comprising of $L$. (L.) major strains from Central Asia, Africa, Iran and Middle East.

The two Pakistani populations did not correlate with the geographical origin of the parasites that fell into them. Their analysis was, however, hampered owing to the small number (only 2) of DNA samples available from Balochistan province. The geographical overlap between two genetically isolated populations might be due to introduction of parasites from different foci through human or reservoir migrations and vector sandfly habitat expansion. One of the most important risk factors in the increase of CL worldwide has been the migration of people from endemic regions [28]. The occurrence of different eco-epidemiological situations, different sand fly vectors and different reservoir hosts might be another explanation for the co-existence of two distinct populations in the same geographical area. Two sand fly species, Phlebotomus papatasi and P. salehi, and three rodent species (Meriones hurrianae, Rhombomys opimus, and Tatera indica) are incriminated as vectors and reservoirs, respectively, of $L$. (L.) major parasites in Pakistan [1]. It is assumed, that $L$. (L.) major in Sindh province, Pakistan has distinct epidemiological and biological characteristics. Variations among the samples of $L$. (L.) major from the same endemic area leading to assignment to different populations were previously attributed to differences in sand fly vector populations [29] and reservoir hosts [30]. Indeed, the existence of distinct groups of Pakistani $L$. (L.) major suggests that the extant parasites in Pakistan may have been restricted there for a long time, rather than being recently introduced from elsewhere by human or animal reservoir migration. The same scenario was recently obseved for $L$. (L.) tropica in Morocco [31] where two genetically very distinct coexisting populations within the same focus were identified. Pratlong et al. (1991) [32] speculated that this old focus was colonized by strains of different geographical origins and that these strains diversified into lesser variants apparently by recent mutation. As there is no epidemiological information available about the strains studied herein it is not possible to judge what the underlying reason(s)/factor(s) for the existence of two genetically distinct populations of $L$. (L.) major in Sindh province, Pakistan, is.

Our study demonstrated the possibility and usefulness of performing MLMT using skin biopsy materials from patient tissues that contain only small amounts of Leishmania DNA. We succeeded in amplifying 10 microsatellite loci from 64 clinical DNA samples. Parasite culture is not easy to perform, especially under field conditions, and often not successful. Therefore, assays that can be carried out directly on clinical materials are of great advantage for surveys including high numbers of isolates. In addition, the direct DNA isolation of Leishmania from clinical samples would avoid the potential selection of special parasites during in vitro cultivation.

\section{Conclusions}

To the best of our knowledge, this study is the first one that has investigated the population structure and genetic diversity of $L$. (L.) major in Pakistan by using the MLMT approach. We were able to detect two genetically isolated populations of $L$. (L.) major in Sindh province, Pakistan. Furthermore, our results corroborated the possibility and/or usefulness of genotyping $L$. (L.) major directly from clinical samples [33,34]. A comprehensive study of the epidemiology of CL in Pakistan, including more strains from other regions endemic for CL and 
investigations of possible differences in reservoirs and sand fly vectors, is warranted.

\section{Competing interests}

The authors declare that they have no competing interests.

\section{Authors' contributions}

MZA designed the study, performed microsatellite typing, conducted data analysis and wrote the manuscript. AMB, FRS, JHB, HK, HU and YH collected the skin biopsy samples and isolated the DNA. RN conducted data analysis. GS participated in coordination and helped to draft the manuscript. YH, HK and KK conceived of the study and critically revised the manuscript. All authors have read and approved the final manuscript.

\section{Acknowledgements}

This study was supported in part by Grants-in-Aid for Japan Society for the Promotion of Science (JSPS) Postdoctoral Fellows (23-01096). We are gratefu to JSPS for providing Postdoctoral Fellowship to M.Z. Alam during the period of this study. We thank Amer Al-Jawabreh (Leishmania Research Unit, Jericho, The Palestine Authority) for providing MSA input file of (L.). major strains used in this study for comparison.

\section{Author details}

'Department of Disease Control, Laboratory of Parasitology, Graduate School of Veterinary Medicine, Hokkaido University, Kita 18 Nishi 9, Kita-ku, Sapporo 060-0818, Japan. ${ }^{2}$ Department of Parasitology, Faculty of Veterinary Science, Bangladesh Agricultural University, Mymensingh 2202, Bangladesh. ${ }^{3}$ Department of Dermatology, Shaheed Mohtarma Benazir Bhutto Medical University, Larkana, Pakistan. ${ }^{4}$ Leprosy Centre, Larkana, Pakistan. ${ }^{5}$ Unit of Risk Analysis and Management, Research Center for Zoonosis Control, Hokkaido University, Sapporo 001-0020, Japan. ${ }^{6}$ Institut für Mikrobiologie und Hygiene, Charité Universitätsmedizin Berlin, Berlin, Germany. 'Division of Dermatology, Department of Organ-oriented Medicine, School of Medicine, University of the Ryukyus, Okinawa 903-0215, Japan. ${ }^{8}$ Department of Parasitology, Kochi Medical School, Kochi University, Kochi 783-8505, Japan. ${ }^{9}$ Centro de Biomedicina, Universidad Central del Ecuador and Prometeo Project, SENESCYT, Quito, Ecuador.

Received: 4 May 2014 Accepted: 4 July 2014

Published: 16 July 2014

\section{References}

1. Alvar J, Vélez ID, Bern C, Herrero M, Desjeux P, Cano J, Jannin J, den Boer M, Team WLC: Leishmaniasis worldwide and global estimates of its incidence. PLoS One 2012, 7(5):e35671.

2. Kassi M, Afghan AK, Rehman R, Kasi PM: Marring leishmaniasis: the stigmatization and the impact of cutaneous leishmaniasis in Pakistan and Afghanistan. PLoS Negl Trop Dis 2008, 2(10):e259.

3. Katakura K: Molecular epidemiology of leishmaniasis in Asia (focus on cutaneous infections). Curr Opin Infect Dis 2009, 22(2):126-130.

4. Bhutto AM, Soomro RA, Nonaka S, Hashiguchi Y: Detection of new endemic areas of cutaneous leishmaniasis in Pakistan: a 6-year study. Int J Dermatol 2003, 42(7):543-548.

5. Kolaczinski J, Brooker S, Reyburn H, Rowland M: Epidemiology of anthroponotic cutaneous leishmaniasis in Afghan refugee camps in northwest Pakistan. Trans R Soc Trop Med Hyg 2004, 98(6):373-378.

6. Marco JD, Bhutto AM, Soomro FR, Baloch JH, Barroso PA, Kato H, Uezato H, Katakura K, Korenaga M, Nonaka S, Hashiguchi Y: Multilocus enzyme electrophoresis and cytochrome $B$ gene sequencing-based identification of Leishmania isolates from different foci of cutaneous leishmaniasis in Pakistan. Am J Trop Med Hyg 2006, 75(2):261-266.

7. Myint CK, Asato Y, Yamamoto Y, Kato H, Bhutto AM, Soomro FR, Memon MZ, Matsumoto J, Marco JD, Oshiro M, Katakura K, Hashiguchi Y, Uezato H: Polymorphisms of cytochrome $b$ gene in Leishmania parasites and their relation to types of cutaneous leishmaniasis lesions in Pakistan. J Dermatol 2008, 35(2):76-85.

8. Kuhls K, Chicharro C, Cañavate C, Cortes S, Campino L, Haralambous C, Soteriadou K, Pratlong F, Dedet JP, Mauricio I, Miles M, Schaar M, Ochsenreither S, Radtke OA, Schönian G: Differentiation and Gene Flow among European Populations of Leishmania infantum MON-1. PLOS Negl Trop Dis 2008, 2(7):e261.
9. Schonian G, Mauricio I, Gramiccia M, Canavate C, Boelaert M, Dujardin JC: Leishmaniases in the Mediterranean in the era of molecular epidemiology. Trends Parasitol 2008, 24(3):135-142.

10. Botilde Y, Laurent T, Quispe Tintaya W, Chicharro C, Canavate C, Cruz I, Kuhls K, Schonian G, Dujardin JC: Comparison of molecular markers for strain typing of Leishmania infantum. Infect Genet Evol 2006, 6(6):440-446.

11. Kuhls K, Keilonat L, Ochsenreither S, Schaar M, Schweynoch C, Presber W, Schonian G, Schönian G: Multilocus microsatellite typing (MLMT) reveals genetically isolated populations between and within the main endemic regions of visceral leishmaniasis. Microbes Infect 2007, 9(3):334-343.

12. Al-Jawabreh A, Diezmann S, Müller M, Wirth T, Schnur LF, Strelkova MV, Kovalenko DA, Razakov SA, Schwenkenbecher J, Kuhls K, Schönian G: Identification of geographically distributed sub-populations of Leishmania (Leishmania) major by microsatellite analysis. BMC Evol Biol 2008, 8:183.

13. Lukes J, Mauricio IL, Schonian G, Dujardin JC, Soteriadou K, Dedet JP, Kuhls K, Tintaya KW, Jirků M, Chocholová E, Haralambous C, Pratlong F, Oborník M, Horák A, Ayala FJ, Miles MA: Evolutionary and geographical history of the Leishmania donovani complex with a revision of current taxonomy. Proc Natl Acad Sci U S A 2007, 104(22):9375-9380.

14. Mahnaz T, Al-Jawabreh A, Kuhls K, Schönian G: Multilocus microsatellite typing shows three different genetic clusters of Leishmania major in Iran. Microbes Infect 2011, 13(11):937-942.

15. Bhutto AM, Soomro FR, Baloch JH, Matsumoto J, Uezato H, Hashiguchi Y, Katakura K: Cutaneous leishmaniasis caused by Leishmania (L.) major infection in Sindh province, Pakistan. Acta Trop 2009, 111(3):295-298.

16. Tiwananthagorn S, Bhutto AM, Baloch JH, Soomro FR, Kawamura Y, Nakao R, Aoshima K, Nonaka N, Oku Y, Katakura K: Zoophilic feeding behaviour of phlebotomine sand flies in the endemic areas of cutaneous leishmaniasis of Sindh Province, Pakistan. Parasitol Res 2012, 111(1):125-133.

17. Schonian G, Schweynoch C, Zlateva K, Oskam L, Kroon N, Graser Y, Presber W: Identification and determination of the relationships of species and strains within the genus Leishmania using single primers in the polymerase chain reaction. Mol Biochem Parasitol 1996, 77(1):19-29.

18. Pritchard JK, Stephens M, Donnelly P: Inference of population structure using multilocus genotype data. Genetics 2000, 155(2):945-959.

19. Evanno G, Regnaut $\mathrm{S}$, Goudet J: Detecting the number of clusters of individuals using the software STRUCTURE: a simulation study. Mol Ecol 2005, 14(8):2611-2620.

20. Dieringer DSC: Microsatellite analizer (MSA): a platform independent analysis tool for large microsatellite sets. Mol Ecol Notes 2002, 3:167-169.

21. Kumar S, Tamura K, Nei M: MEGA3: integrated software for Molecular Evolutionary Genetics Analysis and sequence alignment. Briefings Bioinformat 2004, 5(2):150-163.

22. SW: Evolution and the Genetics of Populations, Volume 4 Variability Within and Among Natural Populations. Chicago: The University of Chicago Press; 1978

23. Tibayrenc M, Ayala FJ: The clonal theory of parasitic protozoa: 12 years on. Trends Parasitol 2002, 18(9):405-410.

24. Balloux F, Lehmann L, de Meeus T: The population genetics of clonal and partially clonal diploids. Genetics 2003, 164(4):1635-1644.

25. Rougeron V, De Meeûs T, Hide M, Waleckx E, Bermudez H, Arevalo J, Llanos-Cuentas A, Dujardin JC, De Doncker S, Le Ray D, Ayala FJ, Bañuls AL: Extreme inbreeding in Leishmania braziliensis. Proc Natl Acad Sci U S A 2009, 106(25):10224-10229.

26. Gelanew T, Kuhls K, Hurissa Z, Weldegebreal T, Hailu W, Kassahun A, Abebe T, Hailu A, Schönian G: Inference of population structure of Leishmania donovani strains isolated from different Ethiopian visceral leishmaniasis endemic areas. PLoS Negl Trop Dis 2010, 4(11):e889.

27. Rogers MB, Downing T, Smith BA, Imamura H, Sanders M, Svobodova M, Volf P, Berriman M, Cotton JA, Smith DF: Genomic confirmation of hybridisation and recent inbreeding in a vector-isolated Leishmania population. PLoS Genet 2014, 10(1):e1004092.

28. WHO (World Health Organization). Available from: http://www.who.int/ leishmaniasis/en/ [cited November 2013].

29. Hamarsheh O, Presber W, Abdeen Z, Sawalha S, Al-Lahem A, Schonian G Genetic structure of Mediterranean populations of the sandfly Phlebotomus papatasi by mitochondrial cytochrome $b$ haplotype analysis. Med Vet Entomol 2007, 21(3):270-277.

30. Githure JI, Schnur LF, Le Blancq SM, Hendricks LD: Characterization of Kenyan Leishmania spp. and identification of Mastomys natalensis, 
Taterillus emini and Aethomys kaiseri as new hosts of Leishmania major. Ann Trop Med Parasitol 1986, 80(5):501-507.

31. Schwenkenbecher JM, Wirth T, Schnur LF, Jaffe CL, Schallig H, Al-Jawabreh A, Hamarsheh O, Azmi K, Pratlong F, Schönian G: Microsatellite analysis reveals genetic structure of Leishmania tropica. Int J Parasitol 2006, 36(2):237-246

32. Pratlong F, Rioux JA, Dereure J, Mahjour J, Gallego M, Guilvard E, Lanotte G, Perieres J, Martini A, Saddiki A: Leishmania tropica in Morocco. IV - Intrafocal enzyme diversity. Ann Parasitol Hum Comp 1991, 66(3):100-104.

33. Alam MZ, Kuhls K, Schweynoch C, Sundar S, Rijal S, Shamsuzzaman AK, Raju BV, Salotra P, Dujardin JC, Schonian G: Multilocus microsatellite typing (MLMT) reveals genetic homogeneity of Leishmania donovani strains in the Indian subcontinent. Infect Genet Evol 2009, 9(1):24-31.

34. Motoie G, Ferreira GE, Cupolillo E, Canavez F, Pereira-Chioccola VL: Spatial distribution and population genetics of Leishmania infantum genotypes in São Paulo State, Brazil, employing multilocus microsatellite typing directly in dog infected tissues. Infect Genet Evol 2013, 18:48-59.

doi:10.1186/1756-3305-7-332

Cite this article as: Alam et al:: Population genetics of Leishmania (Leishmania) major DNA isolated from cutaneous leishmaniasis patients in Pakistan based on multilocus microsatellite typing. Parasites \& Vectors 2014 7:332

\section{Submit your next manuscript to BioMed Central and take full advantage of:}

- Convenient online submission

- Thorough peer review

- No space constraints or color figure charges

- Immediate publication on acceptance

- Inclusion in PubMed, CAS, Scopus and Google Scholar

- Research which is freely available for redistribution 